\title{
EFEKTIVITAS PENGGUNAAN JOBSHEET DALAM PEMBELAJARAN KONSTRUKSI JALAN DAN JEMBATAN KELAS XI DESAIN PERMODELAN DAN INFORMASI BANGUNAN (DPIB) DI SEKOLAH MENENGAH KEJURUAN NEGERI 5 BANDUNG
}

\author{
Dedi Purwanto ${ }^{1}$ dan Eddy Susanto ${ }^{2}$ \\ ${ }^{1}$ Pendidikan Teknik Bangunan, FPTK, UPI \\ ${ }^{2}$ Sekolah Menengah Kejuruan Negeri 5 Bandung \\ Email: depoerwanto@gmail.com
}

\begin{abstract}
ABSTRAK
Media pembelajaran Jobsheet merupakan salah satu bentuk median yang digunakan sebagai perantara dalam proses pembelajaran penyaluran informasi untuk memperoleh aspek kognif, afektif dan psikomotor yang lebih baik. Di dalam proses pembelajaran Konstruksi Jalan dan Jembatan Kelas XI DPIB di SMKN 5 Bandung, untuk memudahkan penyampaian materi baik teori maupun praktik perlu digunakan media yang dapat membantu proses pembelajaran yang dapat dijadikan pegangan untuk guru dan siswa di dalam proses praktikum. Media yang digunakan dalam proses pembelajaraan ini berupa Jobsheet. Tujuan penelitian ini ingin mengetahui bagaimana gambaran tingkat efektivitas dengan menggunakan Jobsheet dalam pembelajaran Konstruksi Jalan dan Jembatan Kelas XI DPIB di SMKN 5 Bandung. Metode penelitian yang digunakan adalah metode deskriptif. Sampel yang digunakan dalam penelitian adalah siswa kelas XI DPIB V SMKN 5 Bandung yang berjumlah 34 siswa. Tingkat efektivitas penggunaan Jobsheet dalam pembelajaran Konstruksi Jalan dan Jembatan dilihat dari hasil belajar. Dari hasil analisis bahwa tingkat efektivitas penggunaan Jobsheet dalam pembelajaran menunjukkan hasil yang efektif sebagai media pembelajaran Konstruksi Jalan dan Jembatan di Kelas XI DPIB di SMKN 5 Bandung dengan persentasi sebesar $79,4 \%$.
\end{abstract}

Kata kunci: Efektivitas, Jobsheet

\section{ABSTRACT}

Jobsheet learning media is one form of median that is used as an intermediary in the learning process for distributing information to obtain better cognitive, affective and psychomotor aspects. In the learning process of Road and Bridge Construction Class XI DPIB at SMKN 5 Bandung, to facilitate the delivery of material both theory and practice, it is necessary to use media that can help the learning process that can be used as a guide for teachers and students in the practicum process. The media used in this learning process is a Jobsheet. The purpose of this study was to find out how to describe the level of effectiveness using Jobsheets in learning Road and Bridge Construction Class XI DPIB at SMKN 5 Bandung. The method used is descriptive method. The sample used in the study were students of class XI DPIB V SMKN 5 Bandung, amounting to 34 students. The level of effectiveness of using Jobsheets in learning Road and Bridge Construction is seen from the learning outcomes. From the results of the analysis that the level of effectiveness of using Jobsheets in learning shows effective results as a learning medium for Road and Bridge Construction in Class XI DPIB at SMKN 5 Bandung with a percentage of 79.4\%.

.Keywords: Effectiveness, Jobsheet

\section{PENDAHULUAN}

Sekolah Menengah Kejuruan (SMK) merupakan salah satu lembaga pendidikan menengah yang mempunyai tujuan untuk mempersiapkan siswa menjadi tenaga kerja yang berkompetensi dan mandiri dengan mengutamakan kemampuan dan keterampilan di dalam bidang tertentu sehingga siswa dituntut dapat beradaptasi dengan kondisi dunia lapangan kerja.

Sekolah Menengah Kejuruan Negeri (SMKN) 5 Bandung merupakan salah lembaga pendidikan menengah kejuruan yang menyelenggarakan bidang kompetensi keahlian Desain Pemodelan dan Informasi Bangunan (DPIB) yang mana mempelajari ilmu tentang gambar konstruksi bangunan, 
konstruksi bangunan, pengukuran tanah, gambar konstruksi menggunakan aplikasi komputer baik 2D maupun 3D, desain interior dan eksterior, konstruksi jalan dan jembatan, menghitung RAB, laporan pembangunan, dll Adapun tujuan diselenggarakaanya kompetensi keahlian DPIB ini salah satunya diharapkan siswa dapat melakukan pekerjaan sebagai Drafter/Juru Gambar dalam pekerjaan perencanaan dan pelaksanaan bangunan.

$$
\text { Proses pembelajaran dalam }
$$

pendidikan merupakan salah satu kegiatan melaksanakan kurikulum pada suatu lembaga pendidikan, supaya dapat membantu para siswa mencapai tujuan pendidikan yang telah ditetapkan. Pada dasarnya, tujuan pendidikan tersebut mengantarkan para siswa supaya dapat menuju pada perubahan-perubahan tingkah laku siswa, baik moral, sosial maupun intelektual, agar mereka dapat menjalankan hidup yang mandiri sebagai seorang yang individu dan makhluk sosial.

Dalama proses pembelajaran di SMK, banyak materi ajar yang tidak hanya memiliki satu tujuan dalam pembelajaran namun juga memiliki tujuan lain, yaitu dalam ranah kognitif dan psikomotor. Hal itu menunjukkan bahwasanya, dalam mencapai tujuan pembelajaran siswa SMK yang diharapkan seorang guru mesti dapat memilih penggunaan media/alat bantu ajar yang tepat. Media yang digunakan dalam pembelajaran tidaklah harus mahal atau merupakan alat-alat canggih, namun media yang akan digunakan harus dapat menyampaikan pesan apa yang ingin disampaikan guru terhadap siswanya.

Salah satu yang dipelajari siswa adalah mata pelajaran Konstruksi Jalan dan Jembatan yang mana salah satu tujuannya siswa harus bisa menggambar konstruksi jalan dan jembatan. Untuk mempermudah pengerjaan penggambaran konstruksi jalan dan jembatan maka dibuatlah dalam bentuk Jobsheet dimana siswa dapat mengikuti petunjuk yang ada dalam jobsheet tersebut dan siswa bisa berkonsultasi/asistensi kepada guru bersangkutan.

Efektivitas proses pembelajaran sangatlah ditentukan oleh kemampuan kompetensi guru yang dimiliki dalam pelaksanaan proses pembelajaran. Kemampuan seorang guru yang berpengaruh ialah dengan cara menguasai materi ajar, gaya berpenampilan guru, perencanaan pembelajaran guru, pelaksanaan dan evaluasai pembelajaran serta metode penyampaian materi dalam proses pembelajaran. Salah satu factor mudah dalam menerima pembelajaran adalah dari kompetensi yang dimiliki guru. Melihat perkembangan teknologi yang terjadi dalam dunia pendidikan, proses pembelajaran pada saat ini khususnya pada kondisi sekolah menengah kejuruan (SMK) tidak lagi hanya dengan metode ceramah. Tetapai dengan kemajuan teknologi, guru dituntut memberikan materi ajar dengan menggunakan sarana yang dapat membuat siswa lebih dapat memiliki daya Tarik terhadapat proses pembelajaran.

Metode pembelajaran menjadi salah satu faktor pendukung yang sangat menentukan kesuksesan proses pembelajaran. Dalam metode pembelajaran ada dua aspek yang paling menonjol yaitu metode mengajar dan media pengajaran. Metode mengajar adalah cara yang dapat digunakan oleh seorang pengajar dalam hal ini guru pada saat melaksanakan interaksi dengan siswa dalam peyampaian materi ajar. Sedangkan untuk media pengajaran merupakan alat pendukung pembelajaran yang sangat berfungsi untuk menunjukan 
visualisasi materi ajar dalam proses pembelajaran.

Menurut Tachjar dalam Yahya (2014) berpendapat bahwa Jobsheet adalah suatu media pendidikan yang dicetak (a printed type of teaching aid) yang mendukung instruktur dalam pengajaran keterampilan terutama di workshop, yang isinya merupakan seperangkat pengarahan dan gambar tentang bagaimana cara membuat atau menyelesaikan suatu job. Jobsheet digunakan untuk pemandu atau sebagai pegangan siswa dalam mempelajari dan menguasai salah satu kompetensi yang diajarkan oleh pendidik (Sukardi dalam Yahya, 2014).

Dalam pemilihan media pembelajaran yang akan digunakan, haruslah disesuaikan dengan tujuan daripembelajaran yang akan dilaksanakan, materi ajar, kompetensi guru, serta karakteristik peserta didik. Jobsheet sebagai salah satu media yang dapat digunakan dalam pembelajaran memiliki fungsi kognitif dan fungsi kompensatoris. Fungsi-fungsi tersebut dapat membantu siswa dalam proses pelaksanaan pembelajaran, dengan melampirkan gambar langkah-langkah dalam proses pembelajaran yangakan dilaksanakan.

Komponen-komponen jobsheet antara lain (1) materi pokok kegiatan praktik yang terdiri dari langkah-langkah kegiatan/proses yang harus dilakukan siswa, pembelajaran praktik dengan menggunakan peralatan harus benar, seringkali dilakukan pre-test sebelum siswa praktik; (2) alat evaluasi yang digunakan; dan (3) keselamatan kerja (Sarbiran dalam Yahya, 2014). Menurut Sukardi dalam Yahya (2014) ada dua jenis job sheet yang digunakan dalam pembelajaran praktik yaitu job produksi (productions job) dan job kombinasi (combining exercises and production jobs).
Penelitian ini dilakukan untuk mengetahui tingkat keefektivitasan dengan menggunakan Jobsheet dalam pembelajaran Konstruksi Jalan dan Jembatan Kelas XI DPIB di SMKN 5 Bandung dilihat dari ketuntasan hasil belajar yang dicapai.

\section{METODE}

Metode yang digunakan dalam penelitian ini adalah metode penelitian Deskriptif dengan menggunakan pendekatan kuantitatif, yakni mendeskripsikan mengenai efektivitas dari penggunaan media Jobsheet dalam pembelajaran Konstruksi Jalan dan Jembatan Kelas XI DPIB di SMKN 5 Bandung yang dilihat dari hasil belajar siswa. Sampel yang digunakan dalam penelitian adalah siswa kelas XI DPIB V SMKN 5 Bandung yang berjumlah 34 siswa.

Pelaksanaan pengujian teknik efektifitas adalah Untuk mengetahui tingkat efektivitas penggunaan Jobsheet, dilihat dari ketuntasan hasil belajar siswa dapat dihitung menggunakan rumus:

Keterangan :

$$
P=\frac{n}{N} \times 100 \%
$$

$\mathrm{P} \quad=$ Presentase ketuntasan hasil belajar

$\mathrm{n} \quad=$ Jumlah siswa tuntas

$\mathrm{N}=$ Jumlah siswa keseluruhan

Data yang telah dianalisis selanjutnya dirata-ratakan dan ditafsirkan dengan kriteria interpretasi efektivitas sebagai berikut:

Tabel 1. Kategori Interpretasi Efektivitas

\begin{tabular}{cc}
\hline Persentase (\%) & Kategori \\
\hline $0-20$ & Tidak Efektif \\
$21-40$ & Kurang Efektif \\
$40-60$ & Cukup Efektif \\
$61-80$ & Efektif \\
$81-100$ & Sangat Efektif \\
\hline
\end{tabular}


Adapun Kriteria Ketuntasan Hasil belajar siswa dinyatakan sebagai berikut.

a. Daya serap perorangan, seorang siswa dikatakan tuntas apabila mencapai hasil $\geq 75$ dari maksimal 100 .

b. Daya serap klasikal, suatu kelas dikatakan tuntas apabila telah mencapai minimal $75 \%$ siswa telah mendapat $\geq 75$ (disesuaikan dengan KKM SMKN 5 Bandung).

\section{HASIL DAN PEMBAHASAN}

Untuk mengetahui tingkat efektivitas penggunaan Jobsheet dilihat dari ketuntasan hasil belajar siswa. Data persentase ketuntasan hasil belajar siswa pada aspek kognitif adalah sebagai berikut.

$$
\begin{aligned}
& P=\frac{n}{N} \times 100 \% \\
& =\frac{27}{34} \times 100 \%=79,4 \%
\end{aligned}
$$

Dari hasil ini dapat dikatakan bahwa pada aspek kognitif, ketuntasan hasil belajar siswa mencapai 79,4\%. Jika diinterpretasikan ke dalam kriteria Efektivitas yang ada pada tabel Kategori Interpretasi Efektivitas nilai hasil belajar pada aspek kognitif berada pada kategori Efektif, sedangkan ditinjau dari segi kriteria ketuntasan hasil belajar siswa, siswa belum dikatakan tuntas dikarenakan masih ada beberapa siswa yang belum memenuhi KKM yang telah ditentukan namun secara klasikal sudah dikatakan tuntas dikarenakan lebih dari $75 \%$ siswa telah mendapat nilai $\geq$ 75 (KKM).

Adapun data persentase ketuntasan hasil belajar siswa pada aspek psikomotorik adalah sebagai berikut.

$$
P=\frac{n}{N} \times 100 \%=\frac{34}{34} \times 100 \%=100 \%
$$

\begin{tabular}{|c|c|c|}
\hline No. & Name & Skor \\
\hline 1 & Responden 01 & 80 \\
\hline 2 & Responden 02 & 85 \\
\hline 3 & Responden 03 & 75 \\
\hline 4 & Responden 04 & 70 \\
\hline 5 & Responden 05 & 80 \\
\hline 6 & Responden 06 & 85 \\
\hline 7 & Responden 07 & 70 \\
\hline 8 & Responden 08 & 85 \\
\hline 9 & Responden 09 & 90 \\
\hline 10 & Responden 10 & 75 \\
\hline 11 & Responden 11 & 80 \\
\hline 12 & Responden 12 & 85 \\
\hline 13 & Responden 13 & 85 \\
\hline 14 & Responden 14 & 90 \\
\hline 15 & Responden 15 & 80 \\
\hline 16 & Responden 16 & 75 \\
\hline 17 & Responden 17 & 75 \\
\hline 18 & Responden 18 & 70 \\
\hline 19 & Responden 19 & 80 \\
\hline 20 & Responden 20 & 80 \\
\hline 21 & Responden 21 & 85 \\
\hline 22 & Responden 22 & 70 \\
\hline 23 & Responden 23 & 80 \\
\hline 24 & Responden 24 & 85 \\
\hline 25 & Responden 25 & 70 \\
\hline 26 & Responden 26 & 70 \\
\hline 27 & Responden 27 & 90 \\
\hline 28 & Responden 28 & 80 \\
\hline 29 & Responden 29 & 80 \\
\hline 30 & Responden 30 & 85 \\
\hline 31 & Responden 31 & 85 \\
\hline 32 & Responden 32 & 70 \\
\hline 33 & Responden 33 & 80 \\
\hline 34 & Responden 34 & 85 \\
\hline
\end{tabular}

Tabel 2. Nilai Siswa

Dari hasil ini dapat dikatakan bahwa pada aspek psikomotorik, ketuntasan hasil belajar siswa mencapai 100\%. Jika diinterpretasikan ke dalam kriteria Efektivitas yang ada pada tabel Kategori Interpretasi Efektivitas nilai hasil belajar pada aspek psikomotorik berada pada kategori Sangat Efektif, sedangkan ditinjau dari segi kriteria ketuntasan hasil belajar siswa dinyatakan tuntas baik secara perorangan/individual maupun secara klasikal dikarenakan pada aspek psikomotorik seluruh siswa sudah memenuhi batas KKM.

Jobsheet dirancang bertujuan untuk memberikan petunjuk dan spesifikasi untuk 
siswa dapat mengerjakan kegiatan secara keseluruhan. Jobsheet dapat mencakup langkah-langkah secara mendetail dalam bentuk tahapan kerja dalam pelaksanaan suatu pekerjaan yang akan dilaksanakan oleh siswa.

Jobsheet merupakan media pembelajaran yang sangat cocok digunakan dalam proses pembelajaran praktik terutama disekolah kejuruan khususnya pada kompetensi keahlian keahlian Desain Permodelan dan Informasi Bangunan. Dari beberapa hasil penelitan sebelumnya memperlihatkan penggunaan jobsheet pada mata pelajaran praktik di SMK memperlihatkan hasil nilai yang maksimal sesuai KKM dan semua siswa selesai dapat menyelesaikan tugas sesuai dan tepat pada waktunya. Didalam jobsheet terdapat langkah-langkah yang harus siswa kerjakan sehingga siswa dapat mengerti dan memahami apa yang akan dia lakukan.

Jobsheet merupakan salah satu media yang digunakan untuk kemampuan psikomotor siswa karena jobsheet berisikan langkah-langkah pengerjaan suatu praktik yang harus dilaksanakan siswa. Selain itu di dalam jobsheet juga terdapat gambargambar ilustratif yang dapat memberikan pemahaman tentang gambaran yang ditugaskan yang telah disampaikan guru dan yang akan diterima oleh siswa. Melihat hal itu, penggunaan jobsheet sangatlah efektif untuk meningkatkan keberhasilan proses belajar praktik siswa karena dalam penerapannya materi yang ingin disampaikan dapat meningkatkan psikomotor siswa.

Bersumber dari konsep yang menentukan kriteria pemilihan media bahwa media merupakan bagian dari sistem instruksional secara menyeluruh, sehinga terdapat beberapa kriteria yang perlu diperhatikan dalam pemilihan media pembelajaran. Kriteria pemilihan media harus sesuai dengan tujuan pembelajaran yang akan dicapai siswa DPIB yang biasanya mengacu pada salah satu atau gabungan dari beberapa tujuan pembelajaran pada ranah kognitif, afektif, dan psikomotor. Selain itu, kriteria pemilihan media juga perlu menyesuaikan dengan kemampuan kompetensi guru dalam penggunaan media yang ada. Dalam penggunaan media yang mutahir dan mahal bukanlah suatu jaminan sebagai media yang terbaik dalam mencapai tujuan pembelajaran, tetapi dengan penggunaan media yang sederhana dan praktis tidak menutup kemungkinan bahwasanya dapat mencapai tujuan pembelajaran yang optimal dan lebih baik.

Pada pelaksanaan pembelajaran siswa kompetensi keahlian Desain Permodelan dan Informasi Bangunan, khusunya dalam hal ini adalah mata pelajaran Konstruksi Jalan dan Jembatan memperlihatkan keefektifan jobsheet dalam pelaksanaan proses pembelajarannya.

\section{SIMPULAN}

Berdasarkan hasil penelitian "Efektivitas Penggunaan Jobsheet dalam Pembelajaran Konstruksi Jalan dan Jembatan Kelas XI DPIB di SMKN 5 Bandung", dapat diambil kesimpulan: "Nilai rata-rata hasil belajar siswa dari aspek kognitif sudah memenuhi kriteria ketuntasan minimal walaupun ada beberapa siswa yang belum lulus namun secara keseluruhan ratarata nilai hasil belajar siswa di atas KKM yang telah ditentukan di SMKN 5 Bandung. Dari aspek psikomotorik, hasil belajar siswa pun sudah memenuhi KKM. Efektivitas penggunaan Jobsheet dalam pembelajaran Kontruksi Jalan dan Jembatan dilihat dari 
nilai rata-rata hasil belajar siswa pada aspek kognitif dan psikomotorik sudah memenuhi kriteria ketuntasan minimal yaitu diatas KKM, sehingga dapat dikatakan bahwa penggunaan Jobsheet ini efektif mampu memberikan pemahaman dan keterampilan bagi siswa."

\section{DAFTAR RUJUKAN}

Arikunto, S. (2009). Dasar-Dasar Evaluasi Pendidikan. Jakarta: Bumi Aksara.

Arsyad, Azhar. (2011). Media Pembelajaran. Jakarta: Divisi Buku Perguruan Tinggi Raja Grafindo Persada.

Kustandi, C. (2011). Media Pembelajaran Manual dan Digital. Jakarta: Ghalia Indonesia.

Panggabean, Luhut. (1989). Penelitian Pendidikan. Bandung. Jurusan Pendidikan Fisika Fakultas Pendidikan Matematika dan Ilmu Pengetahuan Alam Universitas Pendidikan Indonesia.

Riduwan. (2012). Belajar Mudah Penelitian. Bandung: Alfabeta.

Rishandi, Y. (2015) Efektivitas Penggunaan Job Sheet Dalam Pembelajaran Ukur Tanah Kelas X Teknik Gambar Bangunan di Sekolah Menengah Kejuruan Negeri 1 Cirebon. DPTS FPTK UPI. Bandung.

Slavin. (2005). Cooperative Learning: theory, research and practice. Terjemahan Narulita Yusron. Bandung: Nusa Media.
Sudjana. (2005). Metoda Statistika. Bandung: Tarsito.

Sudjana. (2007). Penelitian dan Penilaian Pendidikan. Bandung: Sinar Baru Algensindo.

Sugiyono. (2008). Metode Penelitian Kuantitatif, Kualitatif dan R \& D. Bandung: Alfabeta.

Sugiyono. (2013). Metode Penelitian Pendidikan Pendekatan Kuantitatif, Kualitatif, dan R\&D. Bandung: Alfabeta.

Sumardjo, S., Pratama, G. N. I. P., \& Vemantyasto, T. N. (2020). Efektivitas Modul Estimasi Biaya Konstruksi Jalan pada Mata Pelajaran Estimasi Biaya Konstruksi Di SMK N 1 Purworejo. Jurnal Pendidikan Teknik Sipil,2(2), 104116.

Titania, T., \& Widodo, S. (2020). Pengembangan Media Pembelajaran Video Animasi untuk Mata Pelajaran Mekanika Teknik Kelas X Desain Pemodelan dan Informasi Bangunan di SMK N 2 Yogyakarta. Jurnal Pendidikan Teknik Sipil, 2(2), 89-94.

Yahya, M. (2014). Efektivitas Penggunaan Job Sheet pada Pembelajaran Praktik Jurusan Pendidikan Teknik Otomotif FT UNM. Jurnal Pendidikan. 